\title{
Gestão pública da questão ambiental e tessituras das cidades brasileiras: notas preliminares
}

\author{
Raimunda Nonata do Nascimento Santana \\ Universidade Federal do Maranhão (UFMA)
}

\author{
Salviana de Maria Pastor Santos Sousa \\ Universidade Federal do Maranhão (UFMA)
}

\section{Gestão pública da questão ambiental e tessituras das cidades brasileiras: notas preliminares}

Resumo: Este artigo propõe-se a uma reflexão sobre a gestão pública da questão ambiental nas cidades brasileiras. A temática é esboçada através da abordagem de dois temas-chave: os fundamentos da constituição do urbano e seus nexos com a ação destrutiva do meioambiente e os contornos, (im)possibilidades e desafios da gestão pública da questão ambiental no território da cidade. Parte-se de questionamentos sobre a articulação entre as teses da sustentabilidade e da insustentabilidade e de pistas definidoras da configuração da administração das cidades. Relacionam-se elementos teóricos e históricos, enfatizando particularidades pertinentes à sociedade brasileira. Conclui-se pela impossibilidade da contribuição efetiva da gestão pública de feição empresarial para a reversão plena da crise ambiental urbana no Brasil, uma vez que essa forma de gestão é compelida a favorecer o modo predatório de exploração do meio ambiente no contexto das determinações do modo de produção capitalista.

Palavras-chave: Questão ambiental. Cidades. Gestão pública. Sustentabilidade. Insustentabilidade.

\section{Public Administration of the Environmental Issue and the Contextures of Brazilian Cities: Preliminary Notes}

Abstract: This article reflects on the public administration of the environmental issue in Brazilian cities. The theme is approached through two key themes: the foundations of the constitution of urban space and its relations with the destructive action of the environment and surroundings, the (im)possibilities, and challenges of public administration of the environmental issue in the territory of the city. This is based on questions about the articulation between the theses of sustainability and unsustainability and of the elements that define the configuration of the administration of cities. Theoretical and historic elements are related, emphasizing particularities pertinent to Brazilian society. It concludes that it is impossible for public administration of a corporate style to effectively contribute to a complete reversal of the urban environmental crisis in Brazil, given that this form of management is compelled to favor predatory environmental exploitation because of the nature of the capitalist mode of production.

Keywords: Environmental question. Cities. Public Administration. Sustainability. Unsustainability. 


\section{Introdução}

O presente texto trata sobre a gestão pública tomando-se como referência a questão ambiental nas cidades brasileiras. É resultado de reflexões particulares desenvolvidas pelas autoras em seus grupos de pesquisa, Grupo de Avaliação e Estudo da Pobreza e de Políticas Direcionadas à Pobreza (Gaepp) e Grupo de Estudos, Pesquisa e Debates em Serviço Social e Movimento Social (Gserms), vinculados ao Departamento de Serviço Social e articulados ao Programa de Pós-Graduação em Políticas Públicas da Universidade Federal do Maranhão (UFMA), onde pesquisam, dentre outros, os temas gestão pública e cidades brasileiras.

O interesse teórico-analítico que reuniu as pesquisadoras foi a editoração da Revista de Políticas Públicas, v. 15, n. 1, janeiro a junho de 2011, cujo dossiê temático versou sobre "Políticas Públicas, Questão Agrária e Meio Ambiente". Sua organização motivou a escrita deste texto que diz respeito, de modo mais amplo, às contemporâneas relações entre cidade e política e, de modo particular, ao exame dos dispositivos e desafios dos governos quanto às possibilidades de afirmação da dimensão pública das cidades em formas urbanas assentadas, dentre outras tantas contradições, conflitos e dissensos, na regressão da urbanidade e na degradação dos recursos ambientais.

Parte-se da perspectiva teórico-analítica de que, sob o capitalismo, Estado e capital constituem-se, historicamente, em unidade orgânica e que as leis do mercado sobrepõem-se às necessidades ${ }^{1}$ dos trabalhadores. Como nesse modo de produção as lutas sociais são, geralmente, abafadas, através de estratégias de coerção ou de cooptação, há prevalência dos interesses do capital no desenho das ações desenvolvidas pelo Estado, embora estas se apresentem como de interesse coletivo. Parte-se, também, do reconhecimento de que, nos marcos das transformações contemporâneas, a dimensão ambiental da vida social, em face da progressiva ação destrutiva do capitalismo, impôs-se à pesquisa acadêmico-científica e à agenda pública mundial.

Um dos pontos centrais do debate contemporâneo que dão forma à "questão ambiental" e que balizam a pauta dos governos nesse âmbito, ao redor do planeta, é a tensão entre as teses da sustentabilidade versus insustentabilidade, presentes na produção da vida urbana com suas necessidades, seus modos de apropriação e usos do território e suas formas de organizar a produção e o consumo.

\section{Sustentabilidade e insustentabilidade}

A interseção dessas duas teses é o fato de atestarem que, na relação metabólica com a natureza ${ }^{2}$, a "atividade vital lúcida"3 do ser humano vem se constituindo historicamente deletéria porque nela se tende a desconsiderar, conforme Engels (2011, p. 5), que "nada ocorre na natureza em forma isolada. Cada fenômeno afeta a outro, e é por seu turno influenciado por este [...]". De fato, estudos sistematizados por Silva (2010) indicam que já se verifica, em nível planetário, escassez de matérias primas, além de danos sociais, políticos e ideológicos, decorrentes da ação humana.

A noção de insustentabilidade constitui elemento central das correntes teóricas que se filiam ao pensamento crítico. Para estas, o modo de produção capitalista apresenta três características negativas basilares: gera desigualdades de recursos e de poder entre as classes sociais, reforça as diferenças de gênero e étnico-raciais e instiga a exploração crescente dos recursos naturais ${ }^{4}$. Trata-se, em suma, de um modo de produção insustentável na medida em que precisa destruir a natureza para se reproduzir. Como advoga Silva (2010, p. 67), o "planeta é incapaz de prover, indefinidamente, os recursos necessários à reprodução da vida, em condições históricas e sociais balizadas pelo alto nível de produção e consumo". A tese da insustentabilidade é acolhida por diferentes organizações sociais denominadas "ecologistas", "ambientalistas", "verdes", entre outras, e sua vertente mais extrema tem como fundamento básico a ideia de que o planeta estaria marchando para uma calamidade de magnitude irreversível, uma vez que a degradação ambiental não pode ser evitada nos marcos desse modo de produção. Mészáros (1989, p. 27) traduz essa vertente ao lembrar que

[...] a determinação operativa onipresente no sistema capitalista é e continua sendo o imperativo da lucratividade. [...] o sistema como um todo é absolutamente dissipador, e tem de continuar a sê-lo em proporções sempre crescentes.

Nesse sentido, é essencial tornar incômoda a reprodução e a hegemonia do modo de produção capitalista.

De modo geral, as teses da sustentabilidade têm dois argumentos básicos.

O primeiro argumento é teleológico e se fundamenta na ideia de que o respeito à natureza é uma questão de ética a ser consubstanciada na busca do equilíbrio que se daria pela superação do antropocentrismo e pela construção de uma visão biocêntrica. Por conseguinte, em nome do comprometimento com a reprodução da vida do planeta em condições adequadas, a escala e o processo de produção devem ajustar-se a imperativos ecológicos, mesmo quando estes contrariam o crescimento econômico.

De acordo com Boff (2011, p. 1),

[...] a sustentabilidade alcança a sociedade, a política, a cultura, a arte, a natureza, o planeta e a vida 
de cada pessoa. Fundamentalmente, importa garantir as condições físico-químicas e ecológicas que sustentam a produção e a reprodução da vida e da civilização. O que, na verdade, estamos constatando, com clareza crescente, é que o nosso estilo de vida, hoje mundializado, não possui suficiente sustentabilidade. É demasiado hostil à vida e deixa de fora grande parte da humanidade.

O segundo argumento é o da eficiência na utilização dos recursos naturais. O substrato desse argumento é que a crise ambiental é uma responsabilidade dos agentes econômicos e que a preservação ambiental deve ser conciliada com as estratégias do capital para manter e ampliar o nível de desenvolvimento. Nesse sentido, a taxação constituise em freio ao uso predatório dos recursos porque este uso é balizado pela capacidade individual de pagamento.

Santos (2002, p. 344) advoga que um novo contexto mais ampliado, sistêmico e integrado constitui hoje o terreno das políticas públicas, desenvolvimento local, luta contra a segregação e a exclusão, promoção de identidades etc. As autoridades locais ampliam seu campo de ação e desenvolvem novas iniciativas nas áreas do urbanismo, organização urbana, políticas sociais, cultura, ação econômica. Mas, há que se interrogar sobre as possibilidades efetivas de o governo da cidade contribuir, no campo do complexo gestionário público, para a reversão da denominada questão ambiental urbana, objeto privilegiado no presente artigo.

Assim, se, do ponto de vista histórico, às formas específicas de regulação do capital correspondem relações administrativas, coercitivas e normativas particulares, como é possível que sujeitos sociais diversos trabalhadores, empresários, movimentos sociais, partidos políticos, sindicatos, consumidores e gestores públicos - cheguem a um consenso para resolver conflitos de interesses que consubstanciam a questão ambiental nas cidades brasileiras? Como conciliar a justiça comutativa com a justiça distributiva para estabelecer os sistemas de contrapartida na constituição das respostas à questão ambiental nas cidades?

Partindo desses questionamentos que apontam pistas definidoras da configuração do governo, da arte de governar e se materializam em ações constituintes da administração das cidades, a presente argumentação, articulando estudos teórico-documentais e enfatizando particularidades pertinentes à sociedade brasileira, é aqui esboçada através da abordagem de dois temas-chave: a) fundamentos da constituição do urbano e seus nexos com a ação destrutiva do meioambiente, b) contornos, (im)possibilidades e desafios da gestão pública da questão ambiental no território da cidade.

\section{Constituição do urbano e meio ambiente: fundamentos, tendências gerais, relações e particularidades nas cidades do Brasil}

Há muito é sabido que a instauração do urbano nos marcos próprios à ordem do capital e da sociabilidade capitalista, também sob a particularidade da via colonial, fez-se prenhe de contradições. Tratamse dos processos que tornaram a cidade constitutiva das condições gerais da produção em torno das quais se organizaram e se aglomeraram, necessariamente, os meios de reprodução do capital e da força de trabalho. Nesse movimento permanente, são alterados os domínios e as condições ambientais que sustentam a produção e a reprodução da vida, os modos de apropriação e usos do espaço ${ }^{5}$ e a própria experiência urbana, destacando-se aqui o governo da cidade e a presença pública dos seus moradores, como sujeitos sociais em disputa pela cidade.

Na busca da apreensão dos fundamentos da produção do espaço e da problemática urbana no capitalismo, a análise de Lefebvre (1974, 1999, 2008) possibilita a demarcação de contradições ligadas a uma determinação geral: as relações sociais se concretizam, necessariamente, assumindo formas espaciais. Dentre as contradições assinaladas pelo autor, uma se destaca: o espaço é fragmentado, vendido em parcelas e, ao mesmo passo, ocupado globalmente. Para tal, as classes proprietárias e dirigentes contam com um duplo poder: a propriedade privada do solo e a ação do Estado. Mas, as contradições permanecem e ganham expressão, de modo especial, nas lutas sociais urbanas, nas ações público-estatais, nos planos urbanísticos e nas ações privadas dos mercadores de espaço.

Segundo Lojkine (1981), o que caracteriza a cidade capitalista é, de um lado, a concentração cres- 
cente dos meios de consumo coletivos que cria um modo de vida; de outro, a modalidade particular de organização dos meios de reprodução do capital e do trabalho, cujo efeito é apropriado, nesse modo de produção, como força produtiva.

Por sua vez, Santos e Silveira (2010) propõem que ao longo da formação do território de um país objetos naturais são substituídos por objetos fabricados, técnicos, mecanizados e, depois, cibernéticos e informacionais. Através dos objetos técnicos (hidrelétricas, fábricas, portos, estradas de ferro, cidades) o espaço, de acordo com a renovação na sua materialidade, é marcado por estes acréscimos que se definem, hoje, pela sua ubiquidade, universalidade e tendência à unificação.

Essas ideias permitem compreender a cidade como condição essencial da produção do espaço para o capital. Tal determinação se faz mediada pelo mundo da política, para o qual relações mercantis e interesses privados de classe influem na ação estatal, exigindo investimentos, proteção, reconhecimento político e legal. Então, na efervescência de uma multifacetada cultura política e urbana, projetos e sujeitos diversos, elegendo seus desafios, convicções e estratégias, pensam e disputam a cidade. Tornam, assim, a busca de alternativas em relação à questão urbana e à chamada gestão democrática do território citadino - destacando-se a gestão dos recursos ambientais - em desafios amplos e complexos.

Assim, na particularidade da constituição do urbano no Brasil ${ }^{6}$, contraditórias relações entre dinâmicas de crescimento e desenvolvimento, produção econômica e vida social, acesso e negação do direito à cidade, expressões da questão ambiental não cessam de se manifestar. Tais manifestações podem ser encontradas na realização de atividades industriais, portuárias ${ }^{7}$, comerciais e serviços; nos adensamentos urbanos em áreas impróprias para a moradia; na obsolescência da infraestrutura e dos espaços construídos; no descarte inadequado do lixo e resíduos sólidos; na poluição e degradação das frentes de água (mares, nascentes de rios, rios, lagoas e córregos) que banham ou atravessam o território urbano e nos déficits de acesso à terra urbanizada, à moradia adequada e à cobertura de saneamento ambiental ${ }^{8}$.

De fato, nas cidades brasileiras, muitos são os indicadores que contribuem para a tese da impossibilidade de apartar-se à questão ambiental da pobreza urbana, dos modos precários e segregados de morar peculiares à urbanização que se materializam em uma sociedade profundamente desigual.

No contexto de ressurgimento das lutas operárias e populares (LOPES, 2009) e das ações pré-constituintes, no sentido de garantir a inclusão do direito à cidade na Constituição da República Federativa do Brasil de 1988, ressaltam-se dimensões e singularidades das lutas organizadas em torno do ideário da Reforma Urbana. Há que se enfatizar, ainda, a prodigalidade da "máquina tagarela" do Estado brasileiro na proposição de discursos sobre a vida e a gestão urbana. Destaca-se, nesse âmbito, o Capítulo II da Constituição de 1988, os estudos e subsídios à elaboração da Agenda 21 Brasileira, as Conferências da Cidade, o Estatuto da Cidade (Lei n. 10257/2001), a Lei do Fundo Nacional de Habitação de Interesse Social (Lei n. 11.125/2005) e os Planos Diretores Participativos ${ }^{9}$.

Também o Ministério das Cidades vem garantindo a formulação de alguns marcos institucionais e regulatórios para as políticas setoriais urbanas e ambientais ${ }^{10}$. Com a tarefa de formular e executar uma "política de desenvolvimento urbano para o Brasil", este Ministério estruturou-se considerando três questões relacionadas ao território que afetam as populações urbanas: a moradia, o saneamento básico (água, esgoto, drenagem e coleta e destinação de resíduos sólidos) e as questões do transporte. Na formulação da atual Política Nacional de Habitação, a política fundiária para habitação (urbanizar e reconhecer direitos de posses dos assentamentos populares já existentes) representa uma estratégia indicativa do atual estágio da ação Estado brasileiro na busca de respostas à concretização do direito à cidade definido na norma constitucional.

Junta-se a estas conquistas a consagração da proteção ao meio ambiente e ao direito ambiental, como determina a Constituição. Além da proteção através da reparação de danos, este texto constitucional prevê outros mecanismos de preservação e proteção do meio ambiente, a exemplo da educação ambiental e da ampliação conceitual-legal da expressão meio ambiente. Esta, agora, diz respeito não somente ao meio ambiente natural, mas, também, ao meio ambiente artificial (formado pelo espaço urbano construído), ao meio ambiente cultural e ao meio ambiente do trabalho.

Todavia, a despeito da configuração de todas essas inovações político-institucionais, muitas em resposta a movimentos de luta pela cidade, é necessário, também, reconhecer a permanência e os redimensionamentos da questão urbana brasileira e o malogro do urbanismo reformista. De fato, o ideário da Reforma Urbana parece que vem encolhendose, apequenando-se, desconstruindo-se (BURNETT, 2009). Ou seja, na busca da construção de alternativas que revertam antigos e atuais processos de "espoliação urbana" (KOWARICK, 1995) e o estágio alcançado pela degradação ambiental nas cidades, inscrevem-se, com rara nitidez, a complexidade da questão ambiental urbana e os desafios dos governos das cidades no sentido da produção de "cidades sustentáveis". 


\section{Gestão pública da questão ambiental nas cidades brasileiras}

Em notável trabalho sobre a questão do governo, Foucault (1982) situa a ação de governar como a arte de exercer o poder segundo o modelo da economia que, a partir do século 18, passa a designar um nível da realidade, um campo de intervenção centralizado em estudos dos problemas populacionais. Nesse contexto, a família adquire uma dimensão instrumental e a população, tomada a partir dos seus problemas regulares, passa a ser o objeto de ação governamental: número de mortos, doentes, acidentes, grandes epidemias, mortalidade endêmica, espiral do trabalho, da riqueza.

Dessa longa trajetória foram-se constituindo modos específicos de administrar a coisa pública e a cidade até alcançar as atuais e prevalecentes ideia e efetividade da gestão pública nos estados modernos ocidentais. Elas se consubstanciam através de quatro balizas: o desenho ideopolítico privilegiado em determinado contex to histórico, as demandas que fluem para o interior do Estado, a estrutura organizacional disponível em diferentes setores e os meios gestados para dar dinamismo às propostas elaboradas.

No atual contexto histórico, os elementos que conformam o processo de gestão governamental procuram responder aos contornos de certo "contratualismo" moderno cujas balizas são dadas pelo processo de regulação materializado nos Estados-Nação. E é na cidade que as estruturas administrativas do governo, em seus diferentes níveis - federal, estadual e municipal - testam sua capacidade de controle e regulação no território urbano.

De acordo com Santos (1999, p. 85), movido por condições históricas particulares, o governo constitui-se respondendo a "tensões e antinomias que subjazem à contratualização, não resolúveis pela via contratual". São pressupostos que denominam metacontratuais: o regime geral de valores que torna possível designar por sociedade as interações autônomas entre sujeitos livres e iguais; o sistema comum de medidas que possibilita medir e definir as diferenças importantes na relação entre indivíduos e associações; e o espaço-tempo privilegiado que define as escalas e as perspectivas e são mensuradas as interações não estatais e não nacionais, da deliberação política do processo judicial à produção burocrática do Estado.

Do ponto de vista histórico à forma de administração empresarial predominante no século 20, produção em massa, particularmente em países capitalistas do centro, correspondeu uma ação governamental politizada que se voltava para conciliar as demandas da economia com a necessidade de novos serviços, referenciando-se em ideias e métodos do industrialismo fordista. Desse modo, escolas, hospi- tais, habitações eram consolidados a partir de modelos básicos, padronizando-se os componentes e os procedimentos de construção. Tal processo era justificado em função da economia, da equidade e da divisão social do trabalho.

O Estado também tomou emprestado da indústria as ideias de Taylor sobre a organização do trabalho. As tarefas foram divididas e, na medida do possível, desqualificadas de forma que pudessem ser desempenhadas pelo trabalho semiqualificado. Havia uma estrita divisão entre o que os vitorianos chamavam trabalho intelectual e o mecânico, com os administradores determinando como o trabalho tinha de ser feito. Cada função era acompanhada de uma descrição detalhada de como fazê-la e da definição de sua própria taxa de salário, tudo isso sujeito a uma negociação centralizada (MURRAY, 1991, p. 3).

Em contextos de enfrentamento entre sujeitos sociais diversos, autovinculados por complexos padrões de alianças e conflitos, nos diversos campos da luta política, as decisões gerenciais eram transformadas em ações concretas, utilizando-se fluxos de informações e decisões regidos por regras específicas. Nesse modo de regulação, cujo processo de gestão corresponde ao tipo ideal burocrático desenvolvido por Weber (1968), os funcionários, especialistas encarregados de executar as ações do governo, deveriam viver da política e desempenhar sua função sine ira et studio, isto é, sem ressentimentos e sem preconceitos, ao contrário dos políticos que deveriam viver para a política, podendo apaixonarse, tomar partido, lutar (ira et studio).

A partir da década de 70 , do século 20 , com a nova face do processo de organização capitalista representado pelo ressurgimento da lógica liberal, a economia de mercado é introduzida nos domínios públicos. Passa-se, então, a adotar ali a linguagem dos contratos, da competição, da escolha, mudandose a função do Estado, de provedor a comprador de serviços, o que restringe o seu espaço de atuação, tornando direta a relação capital-trabalho.

Para justificar esse movimento, é construído todo um corpo ideopolítico tendo em vista deslegitimar a necessidade de intervenção estatal, centrando-se a crítica em dois aspectos principais: a forma de administração do Estado e a relação entre os custos da administração do setor público e os benefícios oferecidos. A forma de administração do Estado é denunciada como centralizadora e burocratizada, além de provocar demanda sistemáticas por novos direitos. E os serviços prestados oneram o Fundo Público sem alcançar a eficácia desejada pelos agentes econômicos.

Como solução, passa-se a postular a criação de organismos públicos capazes de responder ao ideal de democracia participativa, agilizando e melhorando a qualidade dos serviços oferecidos. Como lembra Guilhon (2008, p. 6): 
O conjunto de inovações introduzidas no modo de administração estatal até então adotado objetivaria, segundo seus idealizadores, substituir a forma burocrática de gestão pela administração pública gerencial orientada mais por resultados do que procedimentos, tendo como referência o cidadão consumidor, o qual teria sua participação ampliada no contexto das Políticas Públicas enquanto pressuposto do aumento do accountability e da transparência governamental.

Contraditoriamente, técnica e política misturam-se de forma mais visível resultando em um refluxo dos movimentos sociais, maior tecnificação das ações públicas e uma politização da administração. Esta responde incorporando "novas estruturas normativas que trazem para dentro do sistema decisório segmentos que irão demandar regras menos excludentes de convivência social"' (BIZELLI; ALVES, 2008, p. 254).

As expressões concretas da questão ambiental nas cidades brasileiras, seu legado e sua estrutura tornam possível compreender e problematizar a gestão pública nesse âmbito.

No atual contexto histórico, há um sentimento contraditório entre a concepção da natureza como um grande todo do qual o homem faz parte e da natureza como recurso, objeto e base material da indústria e do comércio nas cidades. Esta última perspectiva, visão empobrecida, é a que predomina nos marcos do capitalismo. Como lembra Kosik (1976, p. 67), a natureza "é oficina, laboratório e reserva de matérias-primas, e a relação do homem com ela é a relação do dominador e do criador do material".

É essa concepção de um mundo utilitário que permite a configuração, no presente documento, da questão ambiental também como uma refração da questão social que, analogamente ao que disserta Cerqueira Filho (1982) ${ }^{11}$, trata-se da articulação de problemas políticos, sociais, econômicos e territoriais relacionados ao uso, disponibilidade ou escassez de recursos naturais, no curso da constituição das sociedades modernas.

A gestão pública da questão ambiental, consequentemente, é entendida como administração das atividades relacionadas à utilização racional dos recursos naturais, conservação e preservação da biodiversidade, reciclagem das matérias-primas e diminuição do impacto ambiental.

A pauta do governo nesse campo precisa, portanto, conjugar interesses, conflitos e demandas de diferentes setores e sujeitos sociais e conciliar objetivos que, dependendo das formas de combinação e da correlação de forças sociais, podem ser inconciliáveis com os definidos no artigo 23 da própria Constituição: de um lado, proteger o meio ambiente e combater a poluição em qualquer de suas formas (VI) e preservar as florestas, a fauna e a flora (VII). De outro lado, fomentar a produção agropecuária e organizar o abastecimento alimentar (VIII) e promover programas de construção de moradias (IX).

Os principais instrumentos utilizados pelos gestores públicos brasileiros no processo de gestão da questão ambiental têm sido:

a) a inclusão de propostas relativas ao uso e preservação do meio ambiente nos planos governamentais;

b) o incentivo ao planejamento empresarial, com vistas à diminuição do desperdício de matérias-primas e de recursos escassos, como água e energia, a criação de legislação específica que orienta, inclusive, a prática da responsabilidade pós-consumo das empresas;

c) a aplicação de sanções e indenizações que visam pressionar empresários, trabalhadores e consumidores a buscar meios de desenvolver suas atividades econômicas de maneira mais racional;

d) a administração da opinião pública com a utilização de tecnologias de comunicação voltadas para criar ambiente favorável à preservação do meio ambiente, incentivando o consumidor a escolher mercadorias produzidas por empresas que expressam preocupação ambiental, e, ao mesmo tempo, estimulando as próprias empresas a se adequarem às exigências desse campo.

Junta ou medeia tudo isto, o "urbanismo de resultados"12 e uma dada tendência de planejamento urbano, o "planejamento estratégico de cidades" (BORJA; CASTELLS, 1996). São tendências esboçadas, internacionalmente para preparar as cidades a responderem a novos objetivos em sua base econômica, infraestrutura urbana, qualidade de vida, integração social e governabilidade. Essa modalidade de planejamento e gestão também envolve a cidade prescrevendo pautas para governos locais ${ }^{13}$ e a vida urbana, dentre elas a aplicação da noção de "sustentabilidade" 14 .

A gestão da questão ambiental traduzida para a realidade brasileira considera, dentre outros, a observância dos seguintes princípios: participação na gestão dos recursos naturais buscando sua integridade e benefícios coletivos; garantia do acesso à informação a todos os interessados nas questões de desenvolvimento e meio ambiente; observação dos princípios de descentralização com a incorporação da gestão municipal, sempre que possível; desenvolvimento da capacidade institucional com vistas a possibilitar a construção democrática; e interdisciplinaridade na abordagem dos recursos naturais promovendo a inserção ambiental nas políticas setoriais em geral (BRASIL, 2000).

Os esforços desenvolvidos na esfera da gestão pública, porém, têm sido irrelevantes no sentido de 
contribuir para a sustentabilidade das cidades brasileiras, considerando-se os determinantes mais gerais do processo de produção capitalista e a correlação de forças em presença francamente favorável à continuidade da atual forma predatória como se desenvolve esse modo de produção no país.

\section{Conclusão}

As reflexões aqui desenvolvidas apontam para a perspectiva de que a vida urbana traduz, necessariamente e ao seu modo, as relações conflitantes entre capital, Estado e usos dos recursos ambientais, situados desde uma escala de grandeza planetária até a microescala do território local. Ou seja, nos fundamentos das relações próprias da adaptação da cidade aos estágios do desenvolvimento das forças produtivas, do trabalho, do mercado e do consumo, engendram-se e reforçam-se os determinantes dos danos causados ao meio ambiente do território no qual a urbanização capitalista se assenta e se expande. Isto significa também a configuração de um campo permanente de tensões entre a "sociedade de consumo" e o discurso da sustentabilidade.

Certamente, a compreensão da relação cidaderecursos naturais, da ação destrutiva da urbanização sobre o meio ambiente e das possibilidades da produção de "cidades sustentáveis", exige demarcações mais particulares.

Um conjunto dessas demarcações guarda relações com os efeitos específicos da urbanização sobre ecossistemas e geossistemas. Outro conjunto mantém nexos com a configuração e o agravamento dos problemas ambientais intraurbanos que comprometem a "sustentabilidade" da cidade. Pensadas essas demarcações na particularidade da sociedade brasileira, à revelia do caráter polarizador de algumas metrópoles e megalópoles, é possível considerar que nas diversas escalas de cidades que formam sua rede urbana - regiões metropolitanas e cidades grandes, médias, pequenas, e, de modo particular, as cidades patrimônio - manifestam-se problemas ambientais e padrões insustentáveis de produção, consumo e vida urbana cotidiana.

No governo das cidades brasileiras, hoje simultaneamente segregadas, segmentadas, polarizadas, violentas e poluídas, enfrentam-se modos de apropriação, domínio e usos do espaço mediante lutas, disputas e negociações, incluindo-se as que propõem o direito à urbanidade-projeto político e apropriação citadina.

São elementos que constituem a base em que se desenvolve processo de gestão pública, assentado no predomínio da gestão de feição empresarial. Nesse caso, dadas as leis coercitivas da competição, os agentes governativos são pressionados a se manter à frente do jogo decisório, harmonizando conflitos, estabelecendo negociações, formulando e desenvolvendo políticas regressivas afastadas, portanto, do marco regulatório, estabelecido na própria área da gestão da questão ambiental brasileira.

Em relação à possibilidade de reversão da crise ambiental urbana no Brasil, essa forma de gestão pública, na medida em que é impelida a favorecer o desenvolvimento de um capitalismo de feição predatória, agravada pelas características próprias à sua expansão na periferia do sistema, apresenta limites e desafios bastante consideráveis no sentido de contribuir para a concretização da tese da sustentabilidade nos territórios urbanos.

\section{Referências}

ACSELRAD, H. Introdução. In:___ (Org.). A duração das cidades: sustentabilidade e risco nas políticas urbanas. Rio de Janeiro: DP\&A Editora, 2001, p. 27-55.

ARANTES, O. Uma estratégia fatal: a cultura nas novas gestões urbanas. In: ARANTES, O.; VAINER, C.; MARICATO, E. (Org.). A cidade do pensamento único: desmanchando consensos. Rio de Janeiro: Vozes, 2000, p. 11-73.

BIZELLI, J. L.; ALVES, J. X. S. Planejamento estatal, gestão participativa e regulação do território urbano. In: FONSECA, F.; GUEDES, A. M. (Org.). Controle social da administração pública. Rio de Janeiro: FGV, 2008, p. 129-160.

BOFF, L. Sustentabilidade e cuidado: um caminho a seguir. Disponível em: <envolverde.com.br/.../sustentabilidade-ecuidado-um-caminho-a-seg. >. Acesso em: 9 out. 2011.

BORJA, J.; CASTELLS, M. As cidades como atores políticos. Novos Estudos CEBRAP, São Paulo, n. 45, p. 53-174, jul., 1996.

BRASIL. Ministério do Meio Ambiente. Gestão dos recursos maturais. Brasília: Edições IBAMA, 2000.

BURNETT, F. L. Da tragédia urbana à farsa do urbanismo reformista: a fetichização dos Planos Diretores Participativos. 2009. 526 f. Tese (Doutorado em Políticas Públicas) - Programa de Pós-Graduação em Políticas Públicas/UFMA, São Luís, 2009.

CERQUEIRA FILHO, G. A questão social no Brasil: crítica do discurso político. Rio de Janeiro: Civilização Brasileira, 1982.

DOYAL, L.; GOUGH, I. O direito à satisfação das necessidades. Lua Nova, revista de cultura e política, n. 33, p. 97-121, 1994.

ENGELS, F. O papel do trabalho na transformação do macaco em homem. Disponível em: <http://www.marxists.org/portugues/ marx/1876/mes/macaco.htm>. Acesso em: 8 out. 2011. 
FOUCAULT, M. Microfísica do poder. Organização e tradução de Roberto Machado. Rio de Janeiro: Graal. 1982.

GUILHON. M. V. Administração empresarial e pública: um esforço de desvendamento de suas relações. In: ENCONTRO NACIONAL DE PESQUISADORES EM SERVIÇO SOCIAL, 10, 2008. Anais... Recife: ABEPSS, 2008.

HARVEY, D. Espaços de esperança. São Paulo: Edições Loyola, 2004.

HELLER, A. Teoria de las necessidades en Marx. Barcelona: Península, 1998.

KOSIK, K. Dialética do concreto. Rio de Janeiro: Paz e Terra, 1976.

KOWARICK, L. A espoliação urbana. Rio de Janeiro: Paz e Terra, 1985.

LEFEBVRE, H. La production de l' espace. Paris: Anthropos, 1974.

A cidade do capital. Tradução de Maria Helena Rauta Ramos e Marilena Jamur. Rio de Janeiro: DP\&A editora, 1999.

O direito à cidade. Tradução de Rubens Eduardo Frias. São Paulo: Editora Centauro, 2008.

LOJKINE, J. O Estado capitalista e a questão urbana. Tradução de Estela dos Santos Abreu. São Paulo: Martins Fontes, 1981

LOPES, J. B. As lutas sociais nas transformações contemporâneas: tendências e incidência no Serviço Social no Brasil. Projeto de Pesquisa, DESES/UFMA. São Luís, 2009.

MARICATO, E. Posfácio. In: DAVIS, M. Planeta favela. Tradução de Maria Beatriz Medina. São Paulo: Boitempo, 2008, p. 223.

MARX, K. Manuscritos econômicos filosóficos. Tradução de Alex Marins. São Paulo: Martin Claret, 2001.

MASLOW, A. Hierarquia de necessidades de Maslow. Disponível em: $<$ http://www.sobreadministracao.com/a-piramide-hierarquiade-necessidades-de-maslow/>. Acesso em: 9 out. 2011.

MÉSZÁROS, I. Produção destrutiva e Estado capitalista. Tradução de Georg Toscheff. São Paulo: Ensaio, 1989.

MONIÉ, F.; VIDAL, S. M. do S. C. Cidades, portos e cidades portuárias na era da integração produtiva. Revista de Administração Pública, Rio de Janeiro, v. 40, n. 6, p. 975-995, 2006.

MURRAY, R. The State after Henry. Marxism Today, Oxford: Blackwell, n. 35, p. 22-27, may 1991.
OLIVEIRA, F. de. O Estado e o urbano no Brasil. Espaço \& Debates, São Paulo, n. 6, p. 36-54, jun./set. 1982.

PEREIRA, P. A. Necessidades humanas: subsídios à crítica dos mínimos sociais. São Paulo: Cortez, 2000.

ROUSSEAU, J. J. Discurso sobre a origem e os fundamentos da desigualdade entre os homens. Tradução de Maria Ermantina Galvão. São Paulo: Martins Fontes, 1999.

SANTOS, B. de S. Reinventar a democracia: entre o précontratualismo e o pós-contratualismo. In: OLIVEIRA, F. de; PAOLI, M. C. (Org.). Os sentidos da democracia: políticas do dissenso e hegemonia global. Petrópolis: Vozes, p. 83-112.

. (Org.). Democratizar a democracia: os caminhos da democracia participativa. Rio de Janeiro: Civilização Brasileira. 2002.

SANTOS, M.; SILVEIRA, M. L. Território e sociedade no início do século XXI. São Paulo: Record, 2010.

SILVA, Maria das Graças e. Questão ambiental e desenvolvimento sustentável: um desafio ético-político ao Serviço Social. São Paulo: Cortez, 2010.

VAINER, C. B. Pátria, empresa e mercadoria: notas sobre a estratégia discursiva do planejamento estratégico urbano. In: ARANTES, O.; VAINER, C. B.; MARICATO, E. A cidade do pensamento único: desmanchando consensos. Rio de Janeiro: Vozes, 2000, p. 75-103.

As escalas do poder e o poder das escalas: o que pode o poder local? Cadernos IPPUR/UFRJ, v. XV, n. 2, 2001; v. XVI, n. 1, 2002, p. 13-32.

WEBER, M. Ciência e política: duas vocações. São Paulo: Cultrix, 1968.

\section{Notas}

1 O debate sobre as necessidades humanas é carregado de tensões. Até que ponto essas necessidades devem ser satisfeitas com base em uma hierarquia, tal como estabelecida por Maslow (2011): fisiológicas; segurança; sociais; status/estima; autorrealização? O Estado deve ser o provedor das condições, particularmente, para o atendimento de necessidades básicas (PEREIRA, 2000). Bens e serviços devem ser ofertados de forma universal ou seletiva? Doyal e Gough (1994). Sobre necessidades humanas, conferir também Rousseau (1999), Heller (1998).

2 Ao tratar dessa relação metabólica entre o homem e a natureza, Mészáros (1989) lembra que é o trabalho que faz a mediação entre a esfera da necessidade e de sua realização, a esfera dos questionamentos e das respostas a eles elaboradas. É ele que torna possível o salto ontológico entre os seres anteriores e o ser que se 
torna social. Sua realização, enquanto ato consciente, é que torna possível o processo de humanização e de emancipação, no contexto do qual as diferentes expressões da vida ganham sentido.

3 Conferir Marx (2001).

4 Sobre o tema, conferir Santos (2002).

5 Harvey (2004, p. 80-81) apoiado na premissa de que estratégias espaciais, elementos geopolíticos e desenvolvimentos geográficos desiguais são, historicamente, dimensões vitais da acumulação do capital e da dinâmica da luta de classes argumenta: [...] O capitalismo não pode sobreviver sem seus "ajustes espaciais". O capitalismo tem recorrido repetidas vezes à reorganização geográfica (tanto em termos de expansão como de intensificação) como solução parcial para suas crises e seus impasses. Assim, ele constrói e reconstrói uma geografia à sua própria imagem e semelhança. Constrói uma paisagem geográfica distinta, um espaço produzido de transporte e comunicações, de infraestrutura e de organizações territoriais que facilitam a acumulação do capital numa fase de sua história, apenas para ter de ser desconstruído e reconfigurado a fim de abrir caminho para uma maior acumulação num estágio ulterior [...].

6 Recorde-se que, de acordo com Oliveira (1982), na formação sóciohistórica brasileira, o caráter de produção agroexportadora com base escravista determinou a configuração de um modo de urbanização polarizada. De um lado, a urbanização pobre, e, de outro, poucas e grandes cidades. Tal modo de urbanização se fez diversamente do ocorrido em muitos países da Europa, quando dinâmicas de urbanização se efetivaram no entorno - uma imensa cadeia de aldeias e pequenas vilas - das próprias regiões produtoras de bens primários de exportação. Então, essa particularidade das bases da urbanização no Brasil, gerou, em termos relativos, grandes centros urbanos, desde o seu princípio.

7 Segundo Monié e Vidal (2006, p. 278): “O alargamento da cadeia produtiva impõe às cidades portuárias enfrentamentos complexos que vão desde questões estruturais e instrumentais do próprio cais, até o embate com questões socioeconômicas e ambientais, antes tratadas isoladamente e desconsideradas da cadeia produtiva, bem como a definição de políticas e instrumentos necessários à gestão do porto e da cidade [...]".

8 Diagnósticos sobre água, esgotos e resíduos sólidos constantes do Sistema Nacional de Informações sobre Saneamento (SNIS) da Secretaria Nacional de Saneamento Ambiental do Ministério das Cidades reúnem dados empíricos que permitem inferir a gravidade dos impactos da ausência ou precariedade desses serviços no meioambiente. Estão disponíveis em: 〈http://www.snis.gov.br〉. Acesso em: 7 out. 2011.

9 A Constituição e todas as leis citadas estão disponíveis em: $<$ http:/ /www2.planalto.gov.br/presidencia/legislacao $>$. Acesso em: 11 out. 2011.

10 Conforme registra Maricato (2008, p. 223), “o serviço de água e esgoto no país é um dos mais atraentes mercados para as empresas internacionais, e não faltaram tentativas de mudança do marco regulatório de modo a ampliar as possibilidades de privatização desde o início dos anos 1990. No entanto, graças à resistência localizada num movimento de técnicos reunidos em torno da Frente Nacional de Saneamento (FNS), isso não aconteceu. Desde 1985, coma extinção do Plano Nacional de Saneamento Básico (Planasa), até 2006, o país ficou sem regras claras para o desenvolvimento do setor devido á queda de braço entre os interesses divergentes."

11 Recorde-seque aquestão socialéuma categoria carregada de tensões. De acordo com Cerqueira Filho (1982), trata-se de problemas políticos, sociais e econômicos que o surgimento da classe operária impôs ao mundo no curso da constituição da sociedade capitalista. Para ele, portanto, a questão social estáfundamentalmente vinculada ao conflito entre o capital e o trabalho.

12 Ver, dentre outros, Arantes (2000) e Vainer (2000).

13 No texto As escalas do poder e o poder das escalas: o que pode o poder local?, Vainer $(2001,2002)$ apresenta fecunda discussão sobre as margens de ação de um governo municipal para introduzir ou liderar mudanças capazes de alterar a correlação de forças entre os diferentes segmentos sociais, bem como as condições materiais e imateriais de vida dos grupos subalternas.

14 De acordo com Acselrad (2001), a aplicação da noção de sustentabilidade ao debate sobre o desenvolvimento das cidades exprime um duplo movimento. Por um lado, certo número de atores sociais da cidade passa a incorporar a temática do meio ambiente, sob o argumento da substancial concentração populacional nas metrópoles, da eclosão de conflitos entre processos de ocupação urbana e o funcionamento das redes de abastecimento de água, entre a configuração dos sistemas de transporte e a qualidade do ar, entre outros. Por outro lado, a própria carteira ambiental dos projetos de agências multilaterais de desenvolvimento como o Banco Mundial, apresenta uma trajetória de urbanização crescente: 0 aporte destas agências ao financiamento da infraestrutura das cidades passa a orientar-se pelo critério do que se entende por melhoria da "qualidade ambiental da vida urbana". 
Raimunda Nonata do Nascimento Santana nonatasantana@gmail.com

Doutora em Serviço Social pela Universidade Federal do Rio de Janeiro (UFRJ)

Professora Associada III do Departamento de Serviço Social da Universidade Federal do Maranhão (UFMA)

Salviana de Maria Pastor Santos Sousa salvi200@globo.com

Doutora em Políticas Públicas pela UFMA

Professora Associada III do Departamento de Serviço Social e do Programa de Pós-Graduação em Políticas Públicas da UFMA

UFMA - Departamento de Serviço Social Avenida dos Portugueses, s/n

Campus do Bacanga

São Luís - Maranhão

CEP: 65085-580 